\title{
A Study of the Promotion Effect of Industrial Design on Product Innovation of Small and Medium-sized Manufacturing Enterprises
}

\author{
Yao Shanliang ${ }^{1}$, Yin Haoyang ${ }^{2}$ \\ School of Art \& Design, Wuhan Institute of Technology \\ Wuhan 430205
}

\begin{abstract}
Small and medium-sized manufacturing enterprises face the problem of insufficient product innovation capabilities to integrate market with innovation. Many enterprises do not realize that industrial design can bring strong market competitiveness and potential economic benefits. Therefore, by studying the product innovation in the development process of small and medium-sized manufacturing enterprises, this paper expounds the role of the industrial design in promoting product innovation of these enterprises, and suggests small and medium-sized manufacturing enterprises to use industrial design to promote product innovation.
\end{abstract}

Keywords-Industrial design; Small and medium-sized manufacturing enterprises; Product innovation

\section{INTRODUCTION}

Based on the researches on industrial design promoting product innovation of small and medium-sized enterprises, this paper analyzes the current problems existing in the development of these enterprises, and then analyzes and studies these problems in combination with existing industrial product cases. In the end, on the basis of the theory of industrial design, the paper puts forward a method of using industrial design to promote the product innovation of these enterprises so as to improve the management of industrial design by the enterprises, thereby making product innovation are better developed and applied in enterprises.

\section{Product InNOVATION PROBLEMS FACED By SMALL AND MEDIUM-SIZED MANUFACTURING ENTERPRISES}

\section{A. Limited product innovation capability}

In the early stages of development, small and medium-sized manufacturing companies usually borrow, model, and quote products from others. Some companies even directly improve the design of existing products in the market, or reconstruct the design, and then add their own logos, thereby promoting the product as their own independent research and development fruits. Many small and medium-sized manufacturing companies quickly open up the market by virtue of their successful product cases and attract consumers with the advantages of high quality and low price. However, the success achieved in this way is temporary because these companies lack in-depth research on the successful products in the market.
They blindly make improvements in design, which cannot improve the innovative advantage and the core competitiveness If small and medium-sized manufacturing companies cannot keep up with the pace of market renewal and they do not have independent innovation capability, the produced products will not be favored by consumers and these companies will fall into the vicious cycle including investment failures in the early stage, sluggish sales in the middle period, and poor circulation in the late period. Therefore, if a company does not have strong innovation ability, it will be easily eliminated. At this stage, small and medium-sized manufacturing enterprises do have to improve their innovation capabilities.

\section{B. Limited product innovation practices}

In the process of designing products, it is necessary to better transform products according to different consumers. Some companies believe that independent research and development mean they have to take a lot of risks, so they are reluctant to put an extra effort in design. Moreover, too long R\&D and creation time means increasing cost input. Even if related products are designed, they cannot keep up with the demands of the market due to the lack of follow-up financial support, as a result, the products will be soon eliminated. More small and medium-sized manufacturing companies are inclined to invest more in technology of their products, and then design products based on technology, but the different needs of different consumers for the appearance of products are ignored. Actually, the design of the product is a prerequisite for the product to win the market, for the appearance of the product could give consumers psychological hints, extend the product's life cycle and bring the company profits. In addition, the function of the product is the inherent soul of the product, which requires the company keep innovative in technology. If the product cannot successfully attract consumers, it will be more likely to be eliminated. Therefore, SMEs have to combine product innovation and practice, investigate consumers and markets, conduct product innovations based on market trends, and analyze the relationship among technology, function, and design so as to make the industrial design play a better role in promoting their product innovation. 
III. THE ROLE OF INDUSTRIAL DESIGN IN THE DEVELOPMENT OF SME MANUFACTURING ENTERPRISES

\section{A. The Promotion Effect of Industrial Design on Product Design Innovation}

In the process of development, enterprises should think about how to win the trust of consumers and how to acquire higher profits with the least cost. There are many ways for enterprises to improve innovation in design. On the one hand, when designing the appearance of a product, companies should systematically list the appearances of existing products, make more assumptions about the appearances as much as possible, and combine with related theories in design aesthetics. On the other hand, companies should also refer to creative thinking methods, material process theory, etc. to achieve product design innovation. During the process of the product designing, designers' assumptions and presentations of different solutions all enable the company to make breakthroughs in innovation. These conceptual and theoretical assumptions help designers formulate design plans efficiently and reduce design development time so as to improve the efficiency of product development. Functional design is the core of the product design process and it has to be based on technology. [5]Therefore, enterprises should analyze the problems existing in the existing products, list all the components of the technical system, analyze the interrelationships between the systems, and look for innovative points in these relationships, then technological innovation could be achieved. In this stage, therefore, technology and innovation are interdependent. Enterprises should be fully aware of their own strengths and weaknesses, combine their own conditions and market research, and select the best innovation point for design.

\section{B. The Promotion Effect of Industrial Design on Product Function Innovation}

Function innovation of the product plays a significant role in the development process. The function of the product includes many connotations such as practical functions, cognitive functions and aesthetic functions [2]. Analyzing the product function from the perspective of industrial design, it is more reflected in the technical function of the product. That is, the designed product should have its structure, working modes, logic, details, etc. Consequently, the relationships among the production materials need to be handled well, for example, the size, shape, structure area, surface treatment, etc.

The function of the product determines the audiences of the product. Therefore, the company should make a survey of consumers in the early stage of industrial design and divide the consumers according to their psychological needs, because different consumers have different functional requirements about the product. Enterprises should make innovations in the needs of consumers through industrial design. To a certain extent, the further development of the industrial design of enterprises will improve the function of the product, and it is the same the other way round [4].

\section{The Promotion Effect of Industrial Design on Product Technology Innovation}

Innovation is an important way for small and medium sized manufacturing enterprises to maintain long-term viability and enhance competitiveness. The company's innovative approach is also a key factor in its technological innovation. With the progress of science, the industrial design system is also more perfect than before. The company integrates consumer demand, technology, product innovation and other factors so that the product can meet people's needs in all aspects. What's more, the scientific positioning helps the enterprise place limited resources in valuable and key areas, taking this as the basis, the enterprise achieves breakthroughs in technological innovation. This is how small and medium-sized enterprises lay their foundation for success. Especially for those who develop slowly, and many aspects of them are not mature enough, so it is, predictably, serious mistakes in the selection of key areas will not only cause huge waste of resources, but also miss their own opportunities for development and lose their competitive advantage. Therefore, enterprises should stand on their own strategic point of view, comprehensively study and appraise the product design, identify potential innovation opportunities, and rationally analyze the future development trend of product innovation [5].

Product innovation cannot be separated from the designers' ideas, the function of the product, and the technological development as well. For small and mediumsized enterprises, market demand is quite essential for design, which means enterprises should make market research on consumers and products. Product innovation should not be limited to the function, the technical field, the entire product design and consumer needs should be taken into consideration as well.

\section{STRATEGIES IN INDUSTRIAL DESIGN FOR PROMOTING PRODUCT INNOVATION}

\section{A. Improve the awareness of independent innovation of employees}

Companies should invest efforts to design innovation. The purpose of the design is human rather than products. By analyzing market research and consumers, companies develop new products with good design aesthetics and practical functions to make their products be more competitive in the market. The product's life cycle begins from the product entering the market as a commodity, and continues to develop itself until the product is eliminated by the market. The process shows that any product will eventually be replaced by a better product, companies have to persistently develop new products to prolong the period of development, so as to bring more economic benefits for themselves. Besides, companies also have to be innovative, delay the decline of the product, and strengthen existing markets. [1]The competitiveness of an enterprise depends on the consumer's trust and favor for its brand, and products with good design and functional innovation will react to the company's independent innovation. All in all, industrial design plays an important role in the independent innovation of enterprises. Innovation is quite essential for enterprises keeping dynamic. A series of methods 
such as scientific research, technology, craftsmanship, and aesthetics can be used for product design. New products based on consumer research can better meet consumer demand, naturally, more profitability and stronger corporate competitiveness will be acquired.

\section{B. Taking the industrial design as a corporate development strategy}

Against the backdrop of complex landscape worldwide and ever-changing market, small and medium-sized manufacturing companies have to regard the industrial design as a corporate development strategy and cultivate talents with innovative ability, professional design methods and design concepts. All of these, the core requirements for the development of the enterprise, are quite essential. And the core of the development lies in the market position of the product, while the central point of the product lies in the industrial design, which is used to create products. [3]Enterprises treat the industrial design as one of development strategies to improve themselves. The outcome of technology research and development in an enterprise can only be a "product", only by accepting the recreation by industrial design, can it enter the market and transform into a "commodity". While the industrial design should be based on researches and analysis of users, and adopt different design methods to make products have different design performance. Today, people not only require the function of the product, but also hope that the product could have a beautiful appearance and a strong visual experience, and it is easy to use as well. That is, products based on ergonomics can satisfy consumers. Consequently, industrial design should also be combined with the rational use of ergonomics. As the iron theory of the product design, the research object of ergonomics is the relationship among human, machine and environment [6]. For example, it tells us how does the function of the product better interact with user habits in design, how to design a more appropriate shape to reduce users' aesthetic fatigue, how to design a different appearance to meet the needs of different groups in the market. To achieve product innovation and technological innovation, designers have to solve the above problems with design methods.

In the end, the product determines the core position of industrial design in the development of enterprises, for the fact that product sales are directly related to the future of the enterprise. Therefore, sustainability of the product is something that must be considered in the development strategy. As a support for products, sustainability could extend the life cycle of products in a complex market environment, and then bring more sales profits to enterprises in different periods. From another perspective, these factors help to expand the influence of corporate brands and lay a good foundation for the company's future publicity. Likewise, enterprises should also thoroughly analyze the engineering and aesthetics of industrial design, because good design could make the product have a better appearance, and give the product a more scientific structure, which could increase the value of the product, and then bring the same positive results to the company

\section{CONCLUSIONS}

The growth of small and medium-sized enterprises cannot be separated from their investment in industrial design, enterprises should keep innovative, and make the industrial design play an important role in the development. Industrial design could promote innovation in function, technology and design, which will help enterprises gain a competitive advantage in the market, and guide them into a virtuous cycle of development. Therefore, as an important element of the current small and medium-sized enterprises, industrial design innovation is a significant requirement for maximizing the interests of enterprises and improving their core competitiveness [7]. Of course, under this kind of conditions, companies still have to make better planning to lead the market, increase employees' awareness of innovation, and bring in professionals in industrial design. They should also have accurate and clear strategic insights and business development directions. In a word, these enterprises should develop their own advantages through industrial design and make up for their shortcomings. The above problems are important issues need to be dealt with.

\section{REFERENCES}

[1] Cai Lirong. The Significance of Industrial Design to Enterprise Development and Its Innovation Research [J]. Sci-tech Innovation and Productivity, 2017, (6):99-100,103. DOI:10.3969/j.issn.16749146.2017.06.099.

[2] Chen Bingfa. Research on the Design Method of Model-driven product [J].MACHINE BUILDING \& AUTOMATION

[3] Li Gaoda. Industrial Design - Corporate Competitiveness [J].Friend of Science Amateurs, 2012, (26):85-86.

[4] Mao Yunlin, Zhang Yuhong. Design and Innovation [J] Art and Literature for the Masses, 2012, (14):98. DOI:10.3969/j.issn.10075828.2012.14.084.

[5] Chen Tianrong. Design Management and Industrial Product Design [J]. $\begin{array}{lll}\text { Art Panorama, 2009, (8):236. DOI: } 10.3969 / \text { j.issn. } 1002- & \end{array}$ 2953.2009.08.074.

[6] Wang Liqun. Research on Application Technology of Ergonomics [J]. Architectural Engineering Technology and Besign, 2017, (14):334-334. DOI:10.3969/j.issn.2095-6630.2017.14.321.

[7] Yang Luyin. Research on Core Process Identification of Small and Medium-sized Enterprises Based on Core Competence of Enterprises [D]. Sun Yat-sen University, 2009.

[8] Zhang Xuedong. Product Innovation Based on Industrial Design [J]. Precise Manufacturing \& Automation, 2008, (4):1-3. DOI:10.3969/j.issn.1009-962X.2008.04.001.

[9] Li Liying, Gai Yuling, Zhengxia. Discussion on the Design Technology of Industrial Products [J].MACHINERY DESIGN \& MANUFACTURE, 2008, (4):208-209. DOI:10.3969/j.issn.1001-3997.2008.04.088.

[10] Li Qiang. The Promotion of Industrial Design on the Development of Enterprises [J]. Science \& Technology Information, 2011, (1):141. DOI:10.3969/j.issn.1672-3791.2011.01.113. 